Iğdır Üniversitesi Fen Bilimleri Enstitüsü Dergisi, 12(1): 518-526, 2022

Journal of the Institute of Science and Technology, 12(1): 518-526, 2022

ISSN: 2146-0574, eISSN: 2536-4618

Toprak Bilimi ve Bitki Besleme / Soil Science and Plant Nutrition

DOI: $10.21597 /$ jist.977701

Derleme / Review Article

Geliş tarihi / Received: 02.08.2021

Kabul tarihi / Accepted:15.10.2021

Atıf İçin: Yılmaz Ü, 2022. Meralarda Otlayan Hayvanları Tehdit Eden Çayır Tetanisi Riski. Iğdır Üniversitesi Fen Bilimleri Enstitüsü Dergisi, 12(1): 518-526.

To Cite: Yılmaz Ü, 2022. The Risk of Grass Tetany Threatening Grazing Cattles in Grasslands. Journal of the Institute of Science and Technology, 12(1): 518-526.

\title{
Meralarda Otlayan Hayvanları Tehdit Eden Çayır Tetanisi Riski
}

\section{Ülkü YILMAZ ${ }^{1 *}$}

ÖZET: Çayır tetanisi sığır ve koyunlarda kandaki düşük magnezyum eksikliğine bağlı gelişen metabolik bir bozukluktur. Bu bozukluğun başlıca sebebi ise merada otlanılan bitkilerin bazı besin elementi konsantrasyonları arasındaki dengesizliktir. Bu nedenle, meralarda doğal olarak yetişen bitkilerin makro besin elementi konsantrasyonları ve bunların birbirlerine olan oranının bilinmesi hayvan sağlığı açısından önemlidir. Hayvan sağlı̆̆ını tehdit eden bu rahatsızlığın önüne geçebilmek için öncelikli olarak meralarda çayır tetanisi risk durumlarının belirlenmesi ve bu doğrultuda bölgeye özgü uygun gübreleme programları geliştirilmelidir. Bu makale ile çayır tetanisinin nedenleri bitki-toprakhayvan etkileşimleri göz önüne alınarak değerlendirilmiş ve daha önce yapılmış çalışmalar doğrultusunda ülkemizde meraların çayır tetani risk durumları karşılaştırılmıştır.

Anahtar Kelimeler: Çayır tetanisi, Mera, Hayvansal üretim, Hipomagnezemi

\section{The Risk of Grass Tetany Threatening Grazing Cattles in Grasslands}

ABSTRACT: Grass tetany is a metabolic disorder in cattle and sheep due to low magnesium deficiency in the blood. The main cause of this disorder is the imbalance between the nutrient concentrations of the grasses grazing on the grassland. Therefore, it has become a necessity to know the macro nutrient concentration of grasses growing naturally in grasslands and their ratio to each other. In order to prevent this disease that threatens animal health, grass tetany risk situations in grasslands should be determined and appropriate fertilization programs specific to the region should be developed accordingly. In this article, the causes of grass tetany were evaluated by considering plant-soil-animal interactions, and grass tetany risk status of grasslands in our country was compared in line with previous studies.

Keywords: Grass tetany, Grassland, Animal production, Hypomagnesaemi

${ }^{1}$ Ülkü YILMAZ (Orcid ID: 0000-0001-5031-0523), Çankırı Karatekin Üniversitesi, Orman Fakültesi, Orman Mühendisliği Bölümü, Çankırı, Türkiye

*Sorumlu Yazar/Corresponding Author: Ülkü YILMAZ, e-mail: ulkudikmen@karatekin.edu.tr 


\section{GİRiș}

Çayır tetanisi buzağı ve etçil ırk sığırlarda yavaş, sütçül ırk sığırlarda ise hılı gelişen bir rahatsızlıktır (Vallentine, 2000). Laktasyon dönemindeki koyun ve sığırlar, artan magnezyum $\left(\mathrm{Mg}^{+2}\right)$ ihtiyaçları nedeniyle çayır tetanisine karşı oldukça hassastırlar (Roukos ve ark., 2011; Martens ve ark., 2018; Doncel ve ark., 2019; da Silva ve ark., 2020). Özellikle laktasyon başlangıcından sonraki dönemde kandaki $\mathrm{Mg}^{+2}$ seviyesinin sığırlarda $12 \mathrm{mg} / 1$, koyunlarda $5 \mathrm{mg} / 1$ altına düşmesi çayır tetani olasılığını daha da yükseltmektedir (Underwood ve Suttle, 1999). Hayvan sindirim sisteminde $\mathrm{Mg}^{+2}$ 'nin çözünmeyen bir forma dönüşmesi ile hayvan vücudundaki $\mathrm{Mg}^{+2}$ miktarının azalması çayır tetanisine neden olmaktadır (Vallentine, 2000; Kumssa ve ark., 2019). Hayvanlarda $\mathrm{Mg}^{+2}$ alımı rumen içerisindeki çözünür $\mathrm{Mg}^{+2}$ konsantrasyonuna ve rumen epitel hücreleri boyunca apikal membran potansiyeline (AMP) bağlıdır (Şekil 1). Hayvan rumeninde yüksek potasyum $\left(\mathrm{K}^{+}\right)$konsantrasyonu $\mathrm{Mg}^{+2}$ emilimini de engelleyerek $\mathrm{Mg}^{+2}$ seviyesinin düşmesine neden olarak tetani riskini artırmaktadır (Elliot, 2009; Schonewille, 2013; Doncel ve ark., 2019).

Sığır ve koyunlarda sinir sistemini etkileyen çayır tetanisinin tek nedeni $\mathrm{Mg}^{+2}$ eksikliği değildir (Elliot, 2009; Vallentine, 2000; Doncel ve ark., 2019). Yüksek $\mathrm{K}^{+}$içerikli bitkiler, hayvanlarda mineral elektrolit dengesizliğinin yanında iyon antagonizması nedeniyle de $\mathrm{Na}^{+}$eksikliğine de neden olmaktadır (Swerczek, 2018). Bitkilerde $\mathrm{Na}^{+}$içeriği düştükçe hayvanlarda çayır tetanisi görülme riski artmaktadır (Martens ve ark., 2018; da Silva ve ark., 2020). Çayır tetanisi ile ilgili literatürün kapsamlı bir şekilde incelemesi sonucunda sodyumun $\left(\mathrm{Na}^{+}\right)$çayır tetanisini önlemede etkili olduğu anlaşılmıştır.

Bitkiler için $\mathrm{Na}^{+}$gerekli olmasa da hayvanlar için hayati öneme sahiptir (O'Connor ve ark., 2000; Chhabra, 2017). Hayvanlarda yetersiz $\mathrm{Na}^{+}$alımı aldosteron hormonun salgılanmasinı tetikler ve hayvanlarda hem tükürük hem de işkembe sıvısındaki $\mathrm{Na}^{++}$nın azalmasına $\mathrm{K}^{+}$'nin artmasına neden olur (Çizelge 1). İşkembe içerisinde artan $\mathrm{K}^{+}$konsantrasyonu ise $\mathrm{Mg}^{+2}$ 'nin plazmadaki konsantrasyonunun azalmasına neden olur (Schonewille ve ark., 1999). Leonhard-Marek ve ark. (1998), izole edilen işkembe Sıvısında $\mathrm{K}^{+}$konsantrasyonu 25-75 mmol/l olduğunda $\mathrm{Mg}^{+2}$ emiliminin düştüğünü, ancak 75-100 mmol $\mathrm{K}^{+} / 1$ konsantrasyonunda $\mathrm{Mg}^{+2}$ içeriğinde bir değişim olmadığını gözlemlemişlerdir.

Hayvan dokuları için kritik öneme sahip olan $\mathrm{Mg}^{+2}$ ve kalsiyum $\left(\mathrm{Ca}^{+2}\right)$ (Underwood ve Suttle, 1999; Martens ve Stumpff, 2019) elementlerinin eksikliği sindirim sisteminin zayıflamasına (Schonewille, 2013) ve buna bağlı olarak midede gaz oluşmasına neden olmaktadır (Swerczek, 2018). Yeni Zelanda'da yapılan bir çalışmada $\mathrm{Ca}^{+2}$ ve $\mathrm{Mg}^{+2}$ noksanlığının görüldüğü meralarda sığırlar için yeterli tuz sağlandığı takdirde akut şişkinliğinin önüne geçildiği bildirilmiştir (Netthisinghe ve ark., 2020). Benzer şekilde Swerczek, (2018) yüksek nitrat $\left(\mathrm{NO}_{3}^{-}\right)$içermeyen yem bitkileri ve yeterli tuzla beslenen buzağılarda ölüm oranlarının düşük olduğunu ifade etmiştir. Sığırlar azot (N) içeriği bakımından yüksek yem tükettiğinde, işkembede önemli miktarda amonyak $\left(\mathrm{NH}_{3}\right)$ üretilir (Allison ve Chris 2003). İşkembedeki $\mathrm{NH}_{3}, \mathrm{Mg}^{+2}$ yi çözünmeyen hidroksit formuna dönüşmesine neden olarak, hayvanların kan ile dokularında $\mathrm{Mg}^{+2}$ konsantrasyonu azalmasına neden olarak tetani riskini artırır (Allison ve Chris 2003). Bu nedenle, bitkideki besin elementi noksanlığının tespit edildiği meralarda akut şişkinliğinin önüne geçebilmek için hayvanların kolay ulaşabileceği yerlere tuzluklar konulabilir.

Mera vejetasyonu içerisinde yer alan bitkilerin $\left[\mathrm{K}^{+}\right] /\left[\mathrm{Ca}^{+2}+\mathrm{Mg}^{+2}\right]$ oranı çayır tetani riskinin belirlenmesinde kullanılan önemli bir kriterdir (Şahinoğlu, 2010; Gür, 2014; Doncel ve ark., 2019; Kumssa ve ark., 2020). Ĕger bu oran 2,2 ve üzerinde ise ilgili merada otlayan hayvanlarda çayır tetanisi görülme olasılığı artmaktadır (Roukos ve ark., 2011; Hamilton ve ark., 2012; Schonewille, 2013; Tran ve ark., 2018; Kumssa ve ark., 2019; Loudon ve ark., 2021). 
Çizelge 1. $\mathrm{Na}^{+}$eksikliği ve yüksek $\mathrm{K}^{+}$alımında rumen içerisindeki $\mathrm{K}^{+}, \mathrm{Na}^{+}$ve $\mathrm{Mg}^{+2}$ durumları (Martens ve ark., 2018)

\begin{tabular}{lcccc}
\hline & \multicolumn{4}{c}{ Rumen } \\
\cline { 2 - 5 } Yüksek K ${ }^{+}$alımı & $\mathrm{K}^{+}$ & $\mathrm{Na}^{+}$ & Epitel dokudaki potansiyel fark & $\mathrm{Mg}^{+2}$ adsorbsiyonu \\
\cline { 2 - 5 } $\mathrm{Na}^{+}$eksikliği & $\uparrow$ & $\downarrow$ & $\uparrow$ & $\downarrow$ \\
\hline$\uparrow:$ arma, $\downarrow$ : azalma & $\uparrow$ & $\downarrow$ & $\uparrow$ & $\downarrow$ \\
\hline
\end{tabular}

Toprak çözeltisi içerisindeki $\mathrm{Mg}^{+2}$ 'nin bitkiler tarafından alınabilmesinde bazı faktörler etkilidir (Schonewille, 2013). Bu faktörler toprağın tekstürü, pH'sı, kil mineralojisi ve katyon değişim kapasitesidir (Brady ve Weil 2002; Gobat ve ark., 2004; Herrick ve ark., 2006; Dong ve ark., 2012). Toprağa uygulanan $\mathrm{Mg}^{+2}$ içerikli gübreler sonucunda bitkideki $\mathrm{Mg}^{+2}$ artışı çayır tetanisini önlemede yeterli olmayabilir. Düşük fosfor (P) içerikli topraklarda yapılan bir çalışmada, bitkideki $\mathrm{Mg}^{+2}$ konsantrasyonunu artırabilmek için tek başına $\mathrm{Mg}^{+2}$ içerikli gübrelerin uygulanmasının etkili olmadığ P ile birlikte $\mathrm{Mg}^{+2}$ içerikli gübrelerin toprağa uygulanması ile bitkide $\mathrm{Mg}^{+2}$ seviyesinin arttı̆̆ görülmüştür (Lock ve ark., 2000). Ancak fosforlu gübreleme yapılırken de çok dikkat edilmesi gerekir (Macdonald ve ark., 2017). Çünkü fosfor, toprak pH'sı 5,5 altında Fe ve $\mathrm{Al}$ ile $\mathrm{pH}>7,2$ 'de ise $\mathrm{Ca}^{+2}$ ile bağlanarak bitkiler tarafindan alınamaz forma dönüşmektedir (Tisdale ve ark., 1993; McDowell, 1996). Asitli topraklarda dolomit uygulaması ile toprak pH'sı yükseltilerek (6 -7) toprak çözeltisi içerisindeki $\mathrm{Mg}^{+2}$ 'nin bitkilerin tarafından alınabilecek forma getirilmesi sağlanabilir (Whitehead, 2000; Hamilton ve ark., 2012; Schonewille, 2013).

Ayrıca besin elementi içeriği ile ilişkili toprak özelliklerinin zamansal ve uzaysal olarak değişiminin bilinmesi, besin elementlerinin arazide noksanlık oluşturabileceği noktaların belirlenmesinde oldukça önemlidir (Klaus ve ark., 2013). Böylece meralarda daha etkin ve ekonomik bir gübreleme programı oluşturularak hem bitki hem de toprakta besin elementi noksanlıkları önlenmiş olur. Bazı araştırmacılar bitkideki $\mathrm{Mg}^{+2}$ içeriğini artırmak amacıyla toprağı gübrelemek yerine rasyonlara uygun miktarda $\mathrm{Mg}^{+2}$ eklenmesini önermektedirler (Schonewille, 2013; Kumssa ve ark., 2019). Ancak hayvanlara ek olarak $\mathrm{Mg}^{+2}$ takviyesinin maliyeti ayrı bir dezavantaj olarak karşımıza çıkmaktadır. Çayır tetani riskini azaltmak için $\mathrm{Mg}^{+2}$ içerikli ek gıdaların kullanılmasının (Lock ve ark., 2000) maliyeti, gübreleme uygulamalarına göre daha yüksektir (Martens ve ark., 2018). Çayır tetanisi oluşumunu en aza indirmek için mera vejetasyonu içerisinde $\mathrm{Ca}^{+2}$ ve $\mathrm{Mg}^{+2}$ açısından zengin baklagil yem bitki oranları artırılmalıdır (Roukos ve ark., 2011; Doncel ve ark., 2019).

Bitkilerin $\mathrm{Mg}^{+2}$ içeriği iklim koşullarına göre değişkenlik gösterebilir. Bazı iklim koşullarında bitkilerdeki alınabilir $\mathrm{Mg}^{+2}$ konsantrasyonları çok düştüğü için otlayan hayvanlarda tetani riski artmaktadır (Dalley, 2002; Loudon ve ark., 2021). Özellikle bitkilerin yeni büyümeye başladığı erken ilkbahar döneminde bitkideki $\mathrm{K}^{+}$ve $\mathrm{N}$ içerikleri yüksek olduğu için bitkideki $\mathrm{Mg}^{+2}$ eksikliğinin görülme ihtimali daha yüksektir (Whitehead, 2000; Tran ve ark., 2018). Aydin ve Uzun (2008)'un yaptığı bir çalışmada bulutlu ve yağmurlu gün sayısının fazla olduğu Karadeniz Bölgesi ve benzeri koşullarda, hayvanlarda çayır tetanisi riskinin daha yüksek olduğunu ifade etmişlerdir. Ani sıcaklık değişimleri sonucunda oluşan dolu olayları da bitkideki bazı elementlerin azalmasına neden olmaktadır (Doncel ve ark., 2019).

İlkbaharda gerçekleşen don olayları esnasında bitkide alınabilir $\mathrm{N}$ çoğunlukla amonyum formundadır ve bitkideki amonyum $\mathrm{Mg}^{+2}$ ve $\mathrm{Ca}^{+2}$ alımının önemli ölçüde azalmasına neden olarak $\mathrm{NH}_{3}^{-}$ konsantrasyonu artırır (Netthisinghe ve ark., 2020). Yüksek $\mathrm{NH}_{3}^{-}$içerikli bitkilerin otlanması ile hayvan rumeninde $\mathrm{NH}_{3}^{-}$konsantrasyonun artmasına neden olur (Martens ve Schweigel, 2000). Rumen 
içerisindeki yüksek $\mathrm{NH}_{3}^{-}$konsantrasyonu da rumen içi $\mathrm{pH}$ 'nın artmasına neden olarak sığırlarda rumen içerisinde $\mathrm{Mg}^{+2}$ emilimini azaltır (Dalley ve ark., 1997). Amerika'da 2001 yılında yapılan çalışmaya göre, ilkbaharın sonlarında gerçekleşen don olayları sonucunda meradaki bitkilerde $\mathrm{K}^{+}$içeriğinin arttı̆̆ 1 buna bağlı olarak da otlayan hayvanlarda çayır tetanisine bağlı ölümlerin meydana geldiği bildirilmiştir (Swerczek, 2018).

Çizelge 2. Türkiye'de meralarda yapılan çalışma sonuçlarına göre bitkideki $\left[\mathrm{K}^{+}\right] /\left[\mathrm{Ca}^{+2}+\mathrm{Mg}^{+2}\right]$ oranları

\begin{tabular}{|c|c|c|}
\hline Araştırmacılar & Araştırma Alanı & {$\left[\mathrm{K}^{+}\right] /\left[\mathrm{Ca}^{+2}+\mathrm{Mg}^{+2}\right]$} \\
\hline Koç ve ark., (2000) & Erzurum & 2.11 \\
\hline Alp ve ark., (2001) & Balıkesir & 0.93 \\
\hline Alp ve ark., (2001) & Bilecik & 1.20 \\
\hline Alp ve ark., (2001) & Bursa & 1.25 \\
\hline Alp ve ark., (2001) & Canakkale & 0.97 \\
\hline Alp ve ark., (2001) & Edirne & 1.15 \\
\hline Alp ve ark., (2001) & Kırklareli & 0.92 \\
\hline Alp ve ark., (2001) & Kocaeli & 1.00 \\
\hline Alp ve ark., (2001) & Sakarya & 1.23 \\
\hline Alp ve ark. (2001) & Tekirdağ $\propto$ & 1.11 \\
\hline Alp ve ark. (2001) & Yalova & 0.90 \\
\hline Bakoğlu ve Koç (2002) & Erzurum & 1.51 \\
\hline Tekeli ve ark. (2003) & Tekirdağ & 0.91 \\
\hline Orak ve ark. (2004) & Tekirdağ & 1.12 \\
\hline Ayan ve ark. (2006) & Samsun & 2.54 \\
\hline Ates ve ark. (2010) & Tekirdağ & 1.69 \\
\hline Şahin ve ark. (2010) & Erzurum & 0.60 \\
\hline Bayraktar (2012) & Tekirdağ & 1.51 \\
\hline Alatürk (2012) & Çanakkale & 0.54 \\
\hline Gökkuş ve ark., (2013) & Çanakkale & 0.86 \\
\hline Gür (2014) & Tekirdağ & 1.54 \\
\hline Eğritaş ve Önal Aşcı (2015) & Ordu & 0.48 \\
\hline Parlak ve ark. (2015) & Canakkale & 1.55 \\
\hline Aydın ve Başbağ (2017) & Diyarbakır & 1.72 \\
\hline Algan ve Aydın (2017) & Samsun & 0.82 \\
\hline Can ve Ayan (2017) & Samsun & 3.11 \\
\hline Gülümser ve ark., (2017) & Yozgat & 1.56 \\
\hline Gürsoy ve Macit (2017) & Erzurum & 2.49 \\
\hline Özyazici ve Yıldız (2017) & Van & 2.07 \\
\hline Aygün ve ark., (2018) & Eskișehir & 0.53 \\
\hline Karan ve Başbağ (2018) & Elazıı̆ & 1.03 \\
\hline Turan ve ark. (2018) & Siirt & 1.70 \\
\hline Başbağ ve ark., (2019) & Diyarbakır & 0.94 \\
\hline Başbağ ve ark., (2019) & Siirt & 0.95 \\
\hline Başbağ ve ark., (2019) & Şırnak & 0.90 \\
\hline Başbağ ve ark., (2019) & Mardin & 1,12 \\
\hline Başbağ ve ark., (2019) & Batman & 0.74 \\
\hline Başbağ ve ark., (2019) & Şanliurfa & 0.65 \\
\hline Başbağ ve ark., (2019) & Gaziantep & 1.13 \\
\hline Polat ve Bayraklı (2019) & Konya & 0.81 \\
\hline Sahin (2019) & Ordu & 2.13 \\
\hline Başbağ ve ark., (2020) & Adiyaman & 1.15 \\
\hline Başbağ ve ark., (2020) & Diyarbakır & 0.79 \\
\hline Başbağ ve ark., (2020) & Mardin & 1.13 \\
\hline Başbağ ve ark., (2020) & Siirt & 1.13 \\
\hline Başbağ ve ark., (2020) & Şırnak & 1.51 \\
\hline Çaçan ve Arslan (2020) & Bingöl & 0.60 \\
\hline Tüzen Şahin ve ark., (2020) & Samsun & 0.96 \\
\hline
\end{tabular}


Çayır tetanisi, süt ve besi sığırı üretiminde hayvancılığın karşılaştığı en büyük ekonomik sorunlardan biri olarak kabul edilmektedir. ABD'de çayır tetanisi nedeniyle ölen sığırların yıllık maliyetinin yaklaşık 300 milyon dolar (Lock ve ark., 2000), Avusturya' da ise 16 milyon dolar olduğu hesaplanmıştır (Sackett ve ark., 2006). Türkiye'de çayır tetanisini ekonomik açıdan değerlendiren çalışmalar henüz yapılmamış olup çayır tetanisi bakımından riskli meraların belirlenmesine yönelik çalışmalar da sınırlı sayıdadır. Ülkemizde mera vejetasyonun makro ve mikro besin elementi içeriklerine yönelik çalışmalar doğrultusunda belirlenen $\left[\mathrm{K}^{+}\right] /\left[\mathrm{Ca}^{+2}+\mathrm{Mg}^{+2}\right]$ oranları Çizelge 2 ' de verilmiştir. Yapılan bu çalışma sonuçlarına göre çayır tetani riski bakımından en yüksek $\left[\mathrm{K}^{+}\right] /\left[\mathrm{Ca}^{+2}+\mathrm{Mg}^{+2}\right]$ oranı Gürsoy ve Macit (2017), Ayan ve ark. (2006) ile Can ve Ayan (2017) tarafından bildirilmiştir. Tetani bakımından risk taşıyan bu meralarda sadece bitkideki değil toprak ve bu meralarda otlayan hayvanlardaki besin elementi konsantrasyonları belirlenmelidir.

\section{SONUÇ}

Çayır tetanisi hayvan sağlığını tehdit eden ciddi bir problemdir ve bunu önleyebilmek için mera vejetasyonu içerisinde yer alan bitkilerin besin elementi içeriklerinin bilinmesi gerekmektedir. Bitkilerin besin elementi konsantrasyonu yetiştiği toprağın özelliklerine ve iklim koşullarına bağlı olarak değişkenlik gösterir. Bitkilerdeki besin elementi noksanlıklarını gidermek için kaba yem kullanılması maliyetin artmasına ve antagonistik etkiler nedeniyle diğer elementlerin eksikliklerine yol açabilir. Bu nedenle verimli ve sürdürülebilir bir hayvancılığın yapılabilmesi için mera vejetasyonu içerisindeki bitkilerin besin elementi konsantrasyonlarını etkileyen toprak özelliklerinin de çok iyi anlaşılması gerekmektedir. Ekonomik bir hayvancılık yapılabilmesi için meralarda toprak-bitki-hayvan etkileşimleri tüm boyutları ile incelenmelidir. Öncelikli olarak meraların besin elementi konsantrasyonlarına ilişkin bölgesel olarak yüzey haritaları çıkarılmalıdır. Bölgesel olarak meralarda toprak ve bitkideki besin elementi içeriklerine ilişkin bir veri tabanının oluşturulması, çayır tetanisi bakımından riskli bölgelerin tespit edilmesine yardımcı olacak ve bu doğrultuda bölgeye özgü gübreleme programlarının oluşturulmasını sağlayacaktır.

\section{Çıkar Çatışması}

Makalenin yazımının, makalenin tek yazarı olarak tarafından yapıldığını beyan ederim.

\section{KAYNAKLAR}

Alatürk F, 2012. Gübrelemenin Çanakkale İli Meralarında Verim ve Otun Kimyasal Bileşimine Etkileri. Çanakkale Onsekiz Mart Üniversitesi.

Algan D, Aydın İ, 2017. Üstten Tohumlanan Ve Gübrelenen Merada Otların Nitrat Ve Makro Element Içerikleri. Anadolu Journal of Agricultural Sciences, 32(3): 374-382.

Allison J, Chris H, 2003. Controlling Grass Tetany in Livestock.Cooperative Extension Service. College of Agriculture and Home Economics New Mexico 1-4.

Alp M, Kahraman R, Kocabağli N, Özçelik D, Eren M, Türkmen I, Dursun Ş, 2001. Marmara Bölgesi’ndeki Yem Bitkilerinin Mineral Madde Düzeylerinin Saptanmasi ve Koyunlarda Beslenme Bozukluklari ile Ilişkisi. Turkish Journal of Veterinary and Animal Sciences, 25(4): 511-520.

Ates E, Coskuntuna L, Tekeli AS, 2010. Plant Growth Stage Effects on the yield Feeding Value and Some Morphological Characters of the Fiddleneck (Phacelia tanacetifolia Benth.). Cuban Journal of Agricultural Science, 44(4): 425-428.

Ayan I, Acar Z, Mut H, Basaran U, Asci O, 2006. Morphological Chemical and Nutritional Properties of Forage Plants in a Natural Rangeland in Turkey. Bangladesh Journal of Botany, 35(2): 133- 
142.

Aydın A, Başbağ M, 2017. Karacadă̆’’n Farklı Yükseltilerindeki Meraların Durumu ve Ot Kalitesinin Belirlenmesi. Anadolu Tarım Bilimleri Dergisi, 32(1): 74-84.

Aydin I, Uzun F, 2008. The Possibility of Compensating Potential Tetany Hazard Arising from N and K Fertilization to Rangelands by Mg Treatments. European Journal of Agronomy, 29(1): 33-37.

Aygün C, Kara İ, Oral HH, Erdoğdu İ, Atalay AK, Sever AL, 2018. Bazı Çalı Bitkilerinin Sezonluk (İlkbahar Yaz Sonbahar) Yaprak Örneklerindeki Makro ve Mikro Besin Elementi İçerikleri. Bahri Dağdaş Bitkisel Araştırma Dergisi, 7(1): 51-65.

Bakoğlu A, Koç A, 2002. Otlatılan ve Korunan İki Farklı Mera Kesiminin Bazı Toprak ve Bitki Örtüsü Özelliklerinin Karşılaştırılması. F.Ü. Fen ve Mühendislik Bilimleri Dergisi, 14(1).

Başbağ M, Çaçan E, Sayar MS, Fırat M, 2019. Güneydoğu Anadolu Bölgesinin Farklı Lokasyonlarından Toplanan Boynuzlu Geven (Astragalus hamosus L.) Otunun Bazı Kalite Özelliklerinin Belirlenmesi. Uluslararası Tarım ve Yaban Hayatı Bilimleri Dergisi, 5(2): 346-354.

Başbağ M, Sayar MS, Çaçan E, 2020. Güneydoğu Anadolu Bölgesinin Farklı Lokasyonlarından Toplanan Salvia multicaulis VAHL. Türünde Ot Kalite Değerlerinin Belirlenmesi. Turkish Journal of Agriculture - Food Science and Technology, 8(7): 1492-1496.

Bayraktar E, 2012. Taban ve Orman İçi Meralarda Bitki Örtülerinin Verimleri Tür Bileşimi ve Önemli Türlerin Bazı Özellikleri Üzerinde Bir Araştırma (Namık Kemal Üniv). Retrieved from http://acikerisim.nku.edu.tr:8080/xmlui/bitstream/handle/20.500.11776/270/0040144.pdf?sequen ce $=1 \&$ isAllowed $=\mathrm{y}$

Brady NC, Weil RR, 2002. Nature and Properties of Soils. In Prentice Hall: Upper Saddle River NJ (15 Edition).

Can M, Ayan İ, 2017. Domuz Ayrı̆̆ı ( Dactylis glomerata L .) Popülasyonlarında Gelişme Dönemlerine Göre Verim ve Bazı Özelliklerin Değişimi. KSÜ Doğa Bilimleri Dergisi, 20(2): 160-166.

Chhabra S, 2017. Hypomagnesemia in a Herd Fed on High Protein Diet. Journal of Veterinary Medicine and Surgery, 1(1): 1-8.

Çaçan E, Arslan İ, 2020. Ranunculus constantinopolitanus Bitkisinin Bazı Bitkisel Özellikleri Besleme Değeri ve Tohumlarına Ait Çimlenme Oranlarının Belirlenmesi. Türk Tarım - Gıda Bilim ve Teknoloji Dergisi, 8(7): 1553-1558.

Dalley DE, 2002. Diseases of Dairy Animals Noninfectious Grass Tetany. In H. Roginski (Ed.) Encyclopedia of Dairy Sciences (pp. 833-838). Elsevier.

Dalley DE, Isherwood P, Sykes AR, Robson AB, 1997. Effect of in vitro Manipulation of pH on Magnesium Solubility in Ruminal and Caecal Digesta in Sheep. Journal of Agricultural Science, 129(1) 107-111.

Dougherty CT, Wells KL, Mitchell GE, 1995. Sodium in Pasture Species and Grazing Livestock. Cooperative Extension Service University of Kentucky College of Agriculture.Lexington Ky. 40546 28(5).

Eğritaş Ö, Önal Aşcı Ö, 2015. Yaygın Fĭ̆g- Tahıl Karışımlarının Bazı Mineral Madde İçeriğinin Belirlenmesi. Akademik Ziraat Dergisi, 4(1): 13-18.

Elliot M, 2009. Grass Tetany in cattle - Treatment And Prevention. Primefacts (APrIL) 1-4. Retrieved from http://www.dpi.nsw.gov.au/_data/assets/pdf_file/0008/110888/Grass-tetany-in-cattletreatment-and-prevention.pdf

Gökkuş A, Parlak AÖ, Baytekin H, 2013. Akdeniz Kuşağı Çalılı Meralarında Otsu Türlerin Mineral İçeriklerinin Değişimi. Tekirdağ Ziraat Fakültesi Dergisi, 10(1).

Gülümser E, Mut H, Çopur Doğrusöz M, Başaran U, 2017. Baklagil Yem Bitkisi Tahıl Karışımların Ot 
Kalitesi Üzerinde Tohum Oranlarının Etkisi. Selçuk Tarım ve Gıda Bilimleri Dergisi, 31(3): 4351.

Gür M, 2014. Korunan Otlanan ve Sürülüp Terk Edilen Doğal Meraların Bazı işlevleri ile Kimi Ekolojik Faktörler Arasındaki İlişkiler. Namık Kemal Üniversitesi. Fen Bilimleri Enstitüsü, Tarla Bitkileri Anabilim Dalı (137s).

Gürsoy E, Macit M, 2017. Erzurum İli Çayır ve Meralarında Doğal Olarak Yetişen Bazı Baklagil ve Buğdaygil Yem Bitkilerinin Mineral Madde Kompozisyonlarının Belirlenmesi. Alınteri Zirai Bilimler Dergisi, 32(1): 1-9.

Hamilton EJ, Miles RJ, Lukaszewska K, Remley M, Massie M, Blevins DG, 2012. Liming of Two Acidic Soils Improved Grass Tetany Ratio of Stockpiled Tall Fescue Without Increasing Plant Available Phosphorus. Journal of Plant Nutrition, 35: 497-510.

Herrick JE, Bestelmeyer BT, Archer S, Tugel AJ, Brown JR, 2006. An Integrated Framework for science-Based Arid land Management. Journal of Arid Environments. https://doi.org/10.1016/j.jaridenv.2005.09.003

Karan H, Başbağ M, 2018. Korunan ve Otlatılan Meralarda Ot Kalitesinin Karşılaştırılması. Fırat Üniversitesi Mühendislik Bilimleri Dergisi, 30(1): 125-132.

Klaus VH, Hölzel N, Boch S, Müller J, Socher SA, Prati D, Kleinebecker T, 2013. Direct and Indirect Associations Between Plant Species Richness and Productivity in Grasslands: Regional Differences Preclude Simple Generalization of productivity-Biodiversity Relationships. Preslia 85 97-112.

Koç A, Gökkuş A, Bakoğlu A, Özaslan A, 2000. Palandöken Meralarının Farklı Kesimlerinden Alınan Ot Örneklerinde Bazı Kimyasal Özelliklerin Otlatma Mevsimindeki Değişimi. Nternatıonal Animal Nutrition Congress 471-478.

Kumssa DB, Lovatt JA, Graham NS, Palmer S, Hayden R, Wilson L, Broadley MR, 2020. Magnesium Biofortification of Italian Ryegrass (Lolium multiflorum L.) Via Agronomy and Breeding as a Potential Way to reduce Grass Tetany in Grazing Ruminants. Plant and Soil, 457(1-2): 25-41.

Kumssa DB, Penrose B, Bone PA, Lovatt JA, Broadley MR, Kendall NR, Ander EL, 2019. A reconnaissance Survey of farmers' Awareness of Hypomagnesaemic Tetany in UK Cattle and Sheep Farms. PLoS ONE, 14(10): 1-14.

Leonhard-Marek S, Gäbel G, Martens H, 1998. Effects of Short Chain Fatty Acids and Carbon Dioxide on Magnesium Transport Across Sheep Rumen Epithelium. Experimental Physiology, 83(2): 155164.

Lock TR, Kallenbach RL, Blevins DG, Reinbott TM, Crawford RJJ, Massie MD, Bishop-Hurley GJ, 2000. Phosphorus Fertilization of Tall Fescue May Prevent Grass Tetany. Better Crops With Plant Food, 84(3): 12-13.

Loudon KMW, Tarr G, Lean IJ, McLerie L, Leahy N, Pethick DW, McGilchrist P, 2021. Short Term Magnesium Supplementation to Reduce Dark Cutting in pasture Finished Beef Cattle. Meat Science 180(January) 108560. https://doi.org/10.1016/j.meatsci.2021.108560

Lunnan T, Øgaard AF, Krogstad T, 2018. Potassium Fertilization of Timothy-Based Cut GrasslandEffects on Herbage Yield Mineral Composition and critical K Concentration on Soils with Different K Status. Grass and Forage Science, 73(2): 500-509.

Macdonald KA, Penno JW, Lancaster JAS, Bryant AM, Kidd JM, Roche JR, 2017. Production and Economic Responses to Intensification of pasture-Based Dairy Production Systems. Journal of Dairy Science, 100(8): 6602-6619.

Martens H, Leonhard-Marek S, Röntgen M, Stumpff F, 2018. Magnesium Homeostasis in Cattle: 
Absorption and Excretion. Nutrition Research Reviews, 31(1): 114-130.

Martens H, Schweigel M, 2000. Pathophysiology of Grass Tetany and other Hypomagnesemias: Implications for Clinical Management. Veterinary Clinics of North America: Food Animal Practice, 16(2): 339-368.

Martens H, Stumpff F, 2019. Assessment of Magnesium Intake According to Requirement in Dairy Cows. Journal of Animal Physiology and Animal Nutrition, 103(4): 1023-1029.

Masters DG, White CL, 1996. Detection and Treatment of Mineral Nutrition Problems in Grazing Sheep. In Detection and treatment of mineral nutrition problems in grazing sheep. Australian: Canberra.

Mayland HF, Shewmaker GE, 2001. Animal Health Problems caused by Silicon and Other Mineral Imbalances. Journal of Range Management. https://doi.org/10.2307/4003115

McDowell LR, 1996. Feeding Minerals to Cattle on Pasture. Animal Feed Science and Technology. https://doi.org/10.1016/0377-8401(96)00983-2

Netthisinghe A, Galloway H, De Graves F, Agga GE, Sistani K, 2020. Grain Yield and Beef Cow-Calf Growth Performancein Dual-Purpose and Conventional Grain Wheat Production Systems and Stockpiled Tall Fescue Pasturing. Agronomy, 10(10): 1-13.

Netthisinghe A, Galloway H, De Graves F, Agga GE, Sistani K, 2020. Grain Yield and Beef Cow-Calf Growth Performance in dual-Purpose and Conventional Grain Wheat Production Systems and Stockpiled Tall Fescue Pasturing. Agronomy, 10(10): 1-13.

O'Connor MB, Hawke MF, Waller JE, Rotherham JR, Coulter SP, 2000. Salt Supplementation of Dairy Cows. Proceedings of the New Zealand Grassland Association, 62: 49-53.

Orak A, Ates E, Varol F, 2004. Macar Fiği (Vicia pannonica Crantz.)'nin Farklı Gelişme Dönemlerindeki Bazı Morfolojik ve Tarımsal Özellikleri ile Besin İçeriği İlişkileri. Tarım Bilimleri Dergisi, 10(4): 410-415.

Özyazici MA, Yıldız A, 2017. Türkiye'nin Doğusunda Yer Alan Doğal Bir Meranın Toprak ve Bitki Örtüsünün Beslenme Dinamiği. KSÜ Doğa Bilimleri Dergisi, 20(özelsayı): 109-115.

Parlak AÖ, Parlak M, Gökkuş A, Demiray HC, 2015. Akdeniz (Çanakkale) Meralarının Ot Verimi ve Kalitesi ile Botanik Kompozisyonu ve Bazı Toprak Özellikleri. ÇOMÜ Ziraat Fakültesi Dergisi, 3(1): 99-108.

Polat H, Bayraklı F, 2019. Konya Bölgesi Doğal Meraları İçerisindeki Bazı Bitkilerin Ham Protein ve Besin Elementi İçerikleri. Bahri Dağdaş Bitkisel Araştırma Dergisi, 8(1): 132-147.

Roukos C, Papanikolaou K, Karalazos A, Chatzipanagiotou A, Mountousis I, Mygdalia A, 2011. Changes in Nutritional Quality of Herbage Botanical Components on a Mountain Side Grassland in North-West Greece. Animal Feed Science and Technology, 169(1-2): 24-34.

Sackett D, Holmes P, Abbott K, Jephcott S, Barber M, 2006. Assessing the Economic Costofendemic Disease on the Profitability of Australian Beef Cattle and Sheep Producers. Meat and Livestock (MLA) Limited: Sydney.

Schonewille JT, 2013. Magnesium in Dairy Cow Nutrition: An overview. Plant and Soil, 368(1-2): 167178.

Schonewille JT, Van't Klooster AT, Wouterse H, Beynen AC, 1999. Effects of Intrinsic Potassium in Artificially Dried Grass and Supplemental Potassium Bicarbonate on Apparent Magnesium Absorption in Dry Cows. Journal of Dairy Science, 82(8): 1824-1830.

Swerczek TW, 2018. Sodium for the Prevention of Grass Tetany and Fetal Losses Associated with Nitrate Toxicosis in Herbivores. Nutrition \& Food Science International Journal, 8(1): 8-11.

Şahin E, Tosun M, Haliloğlu K, Aydın M, 2010. Yabani Domuz Ayrı̆̆ının (Dactylis glomerata) Oltu Ekotipine Ait Hatlarda Bazı Tarımsal ve Kalite Özellikleri. Ziraat Fakültesi Dergisi, 5(1): 24-35. 
Şahin N, 2019. Ordu İli Yayla Vejetasyonlarında Doğal Olarak Bulunan Makromantarların Bitkilerin Besin Elementi İçeriklerine ve Toprak Özelliklerine Etkisi. Ordu Üniversitesi.Fen Bilimleri Enstitüsü. Yüksek Lisans Tezi. 71s.

Şahinoğlu O, 2010. Bafra İlçesi Koşu Köyü Merasında Uygulanan Farklı Islah Yöntemlerinin Meranın Ot Verimi Yem Kalitesi ve Botanik Kompozisyonu Üzerine Etkileri. Ondokuz Mayıs Üniversitesi. Fen Bilimleri Enstitüsü Tarla Bitkileri ABD. Doktora Tezi.136s.

Tekeli AS, Avcıoğlu R, Ateş R, 2003. İran Üçgülü (Trifolium resupinatum L.)'nde Bazı Morfolojik ve Kimyasal Özelliklerin Zamana ve Toprak Üstü Biomasına Bağlı Olarak Değişimi. Tarım Bilimleri Dergisi, 9(3): 352-360.

Tisdale SL, Nelson WL, Havlin L, 1993. Soil Fertility and Fertilizers (Fifth Edit). New York: Macmillan USA.

Turan N, Özyazıcı MA, Açıkbaş S, Seydoşoğlu S, 2018. Fiğ (Vicia sp.) Cinslerine Ait Genotiplerin Bazı Makro Element Kapsamlarının Belirlenmesi. III. Uluslararası Mesleki Ve Teknik Bilimler Kongresi (October) 3705-3712. Gaziantep.

Tüzen Şahin E, Acar Z, Can M, Ayan İ, 2020. Araştırma Orman üçgülü (Bituminaria bituminosa C. H. Stirt) Bitkisinde Bazı Özelliklerin Mevsimsel Değişiminin Belirlenmesi. Akademik Ziraat Dergisi, 9(1): 93-102.

Underwood EJ, Suttle NF, 1999. The Mineral Nutrition of Livestock (3rd ed.). UK: CABI Publishing.

Vallentine JF, 2012. Grazing Management. In Grazing Management. https://doi.org/10.1016/C2009-0$02468-4$

Whitehead DC, 2000. Nutrient Elements in Grassland. Introduction. In Nutrient elements in grassland: soil-plant-animal relationships. https://doi.org/10.1079/9780851994376.0001. 